\title{
A case of bleomycin-induced lung toxicity
}

\author{
Cuneyt Tetikkurt1, Deniz Ongel1, Seza Tetikkurt² \\ 1 Department of Pulmonary Medicine, Cerrahpasa Medical Faculty, Istanbul University \\ 2 Department of Pathology, Bagcılar Training and Research Hospital, University of Health Sciences, \\ Istanbul, Turkey
}

\begin{abstract}
A 64-year-old female was admitted for dry cough, dyspnea, fever, loss of appetite, and weight loss. Past medical history revealed scoliosis, cholecystectomy, and Hodgkin lymphoma. ABG values were: $\mathrm{pH}$ : 7.42, $\mathrm{pCO}_{2}: 40.2 \mathrm{~mm} \mathrm{Hg}, \mathrm{pO}_{2}: 61.4 \mathrm{~mm} \mathrm{Hg}$. Chest CT showed cystic lesions, emphysema, ground glass, and reticular opacities. ABG values worsened under $8 \mathrm{~L} / \mathrm{min}$ nasal oxygen. The patient underwent bilevel positive airway pressure (BiPAP) and methylprednisolone $60 \mathrm{mg} /$ day bid was commenced. The final diagnosis was respiratory insufficiency due to bleomycin toxicity. The patient deceased on the sixth day after transfer to the intensive care unit. Bleomycin is an effective chemotherapeutic agent used for Hodgkin lymphoma treatment. It causes significant lung toxicity in half of the patients. Clinicians should always remember that bleomycin toxicity may lead to fatal complications in patients with comorbid conditions. We present this case to remark the possible consequences of bleomycin toxicity and the precautions taken to preclude bleomycin-induced pulmonary complications are discussed.
\end{abstract}

Corresponding author: Prof. Cuneyt Tetikkurt, Department of Pulmonary Medicine, Cerrahpasa Medical Faculty, Istanbul University, Tanzimat Sok. Serkan Apt. No:8/16, 34728 Caddebostan, Istanbul, Turkey.

Tel. +90.216 .3601977 - Mobile: +90.532 .3810900 - Fax: +90.212 .5870217 . E-mail: tetikkurt@gmail.com

Key words: Bleomycin; bleomycin-induced lung toxicity; pulmonary fibrosis; bleomycin toxicity.

Contributions: CT, designed and wrote the case report; DO, contributed to reference selection and preparation; ST contributed to pathologic evaluation and wrote the pathogenic mechanisms of bleomycin toxicity.

Conflict of interest: The authors declare no conflict of interest.

Received for publication: 15 July 2018

Accepted for publication: 16 October 2018

(C) Copyright C. Tetikkurt et al., 2018

Tipografia PI-ME Editrice, Italy

Monaldi Archives for Chest Disease 2018; 88:981

doi: 10.4081/monaldi.2018.981

This article is distributed under the terms of the Creative Commons Attribution Noncommercial License (by-nc 4.0) which permits any noncommercial use, distribution, and reproduction in any medium, provided the original author(s) and source are credited.

\section{Introduction}

Bleomycin is a chemotherapeutic agent that was isolated from a strain of Streptomyces verticillus [1,2]. It is frequently used to treat Hodgkin's lymphoma and germinative tumors. The paramount drawback of bleomycin is its high potential to cause pulmonary toxicity that may progress to pulmonary fibrosis occurs in approximately $10 \%$ of the patients [2-6]. Other less common side effects include hypersensitivity and organizing pneumonitis [5-7]. The pathogenesis of bleomycininduced lung injury is not entirely known. Likely components of bleomycin lung injury include oxidative damage, deficiency of bleomycin hydrolase, genetic predisposition, and inflammatory cytokines. Chronic fibrotic response of bleomycin induced lung injury is due to the loss of bleomycin hydrolase activity [8]. Influence of genetic factors for bleomycin-induced lung injury is suggested by the variable clinical profile of bleomycin sensitivity among patients [9-11]. Diagnosis is determined by integration of symptoms, clinical and radiologic findings. The clinical picture may be complicated and enigmatic that requires a thorough evaluation for differential diagnosis.

The potential of bleomycin lung toxicity is well known but the extent of this complication is not well authenticated. Oxidative damage, deficiency of bleomycin hydrolase, genetic predisposition and inflammatory cytokines are the hallmark pathogenetic mechanisms of bleomycin toxicity. This case report will focus on the potential avertible factors associated with the bleomycin-induced lung toxicity and the patient profile that would forestall the severe or fatal complications of bleomycininduced lung injury by disputing the clinical precautions that would prevent the potential pulmonary side effects of bleomycin.

\section{Case Report}

A 64-year-old female patient was admitted for the evaluation of dry cough, dyspnea, fever, loss of appetite, and weight loss of six kilograms during the previous two months. Personal history revealed scoliosis, laparoscopic cholecystectomy, and Hodgkin lymphoma that was treated with doxorubicin, bleomycin, vinblastine, dacarbazine (ABVD) and radiotherapy six months ago. The BLMH A1450G genotype distribution was homozygous wild-type A/G genotype. She was a current smoker with a 50 p/year smoking history. At initial admission she was tachypneic with a respiratory rate of $22 / \mathrm{min}$. Blood pressure was $140 / 70 \mathrm{~mm}$ $\mathrm{Hg}$. Bilateral fine rales were present over the middle and lower lung zones. ECG showed sinus tachycardia of $112 / \mathrm{min}$. WBC: $6.9 \mathrm{X} 10^{3} / \mathrm{mm}^{3}$,

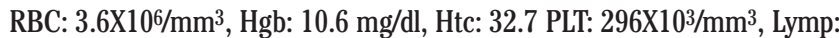

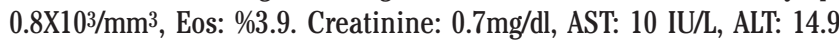
IU/L, LDH: $165 \mathrm{IU} / \mathrm{L}, \mathrm{Na}: 142 \mathrm{mmol} / \mathrm{L}, \mathrm{K}: 4.3 \mathrm{mmol} / \mathrm{Ca}$ : $8.2 \mathrm{mg} / \mathrm{dl}$, and CRP: $2,4 \mathrm{mg} / \mathrm{dl}$. Arterial blood gas (ABG) values on admission were: $\mathrm{pH}$ : $7.42, \mathrm{pCO}_{2}: 40.2 \mathrm{~mm} \mathrm{Hg}$, and $\mathrm{pO}_{2}: 61.4 \mathrm{~mm} \mathrm{Hg}$. Chest $\mathrm{x}$-ray showed interstitial pattern and ground glass opacities at the middle and lower 
lung zones (Figure 1). CT revealed diffuse cystic lesions, ground glass opacities, traction bronchiectasis, and reticular opacities in both lungs (Figures 2 and 3). Sputum smear, cytology, and culture for bacteria, mycobacteria, and fungus were negative. Anti-histone antibody was 4.6 units. Following ABG values in the second day were as follows: $\mathrm{pH}: 7.38$, $\mathrm{pO}_{2}: 52.9 \mathrm{~mm} \mathrm{Hg}$, and $\mathrm{pCO}_{2}: 38.5 \mathrm{~mm} \mathrm{Hg}$ while the patient received nasal $8 \mathrm{~L} / \mathrm{min}$ oxygen. BiPAP was started and intravenous methylprednisolone $60 \mathrm{mg} /$ day bid was commenced. The ABG values on the third day were as follows: $\mathrm{pH}: 7.41, \mathrm{pCO}_{2}: 49.3 \mathrm{~mm} \mathrm{Hg}, \mathrm{pO}_{2}: 49.6 \mathrm{~mm} \mathrm{Hg}$ and $\mathrm{pH}: 7.40, \mathrm{pO}_{2}: 50.1 \mathrm{~mm} \mathrm{Hg}, \mathrm{pCO}_{2}: 49.3 \mathrm{~mm} \mathrm{Hg}$. The patient was transferred to the intensive care unit and mechanical ventilation was started. Final diagnosis was respiratory insufficiency due to bleomycin lung toxicity. The patient deceased on the sixth day of her admission in the intensive care unit.

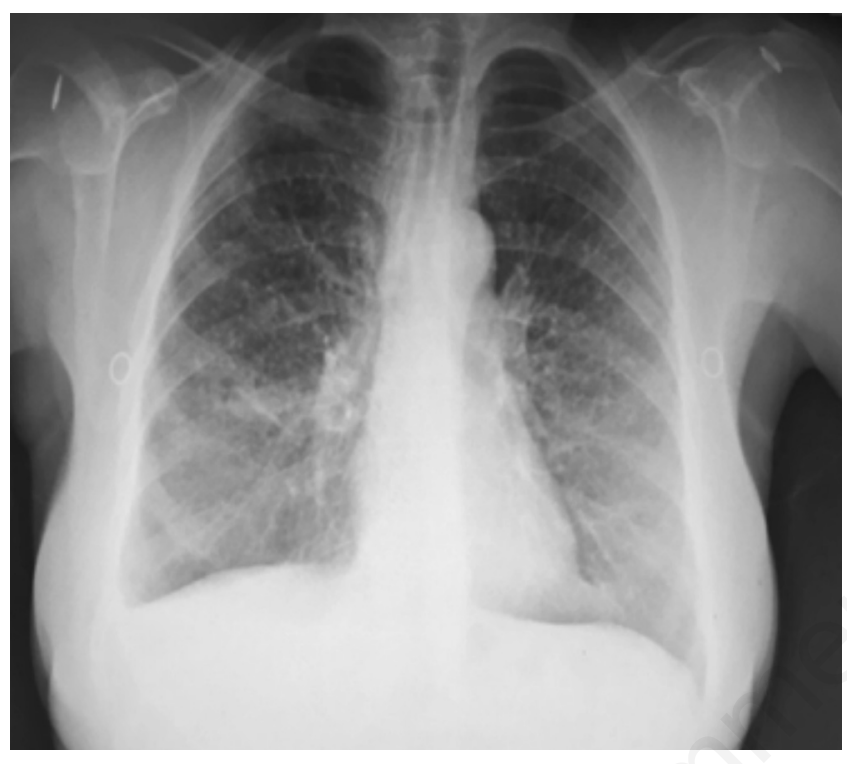

Figure 1. Chest $\mathrm{x}$-ray revealing interstitial pattern and ground glass opacities at the middle and lower lung zones.

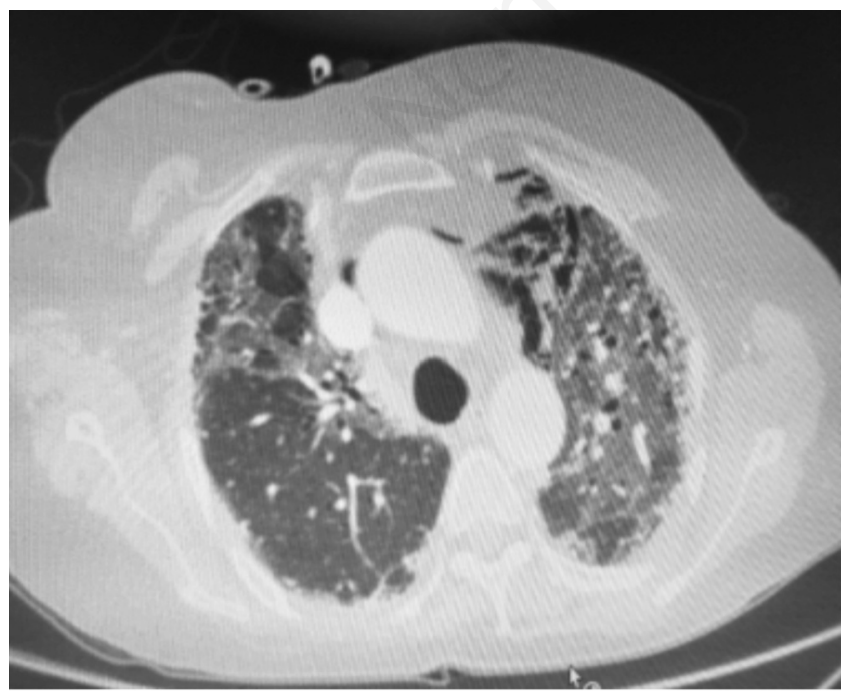

Figure 2. Chest CT showing bilateral diffuse cystic emphysema, ground-glass opacities, traction bronchiectasis, and interstitial fibrosis.

\section{Discussion}

Bleomycin is a chemotherapeutic agent that was isolated from a strain of Streptomyces verticillus in 1966 [1]. The drug is frequently used to treat a variety of malignancies, predominantly germ cell tumors and Hodgkin lymphoma since it does not lead to myelosuppression. The major limitation of bleomycin treatment is the potential for life-threatening interstitial pulmonary fibrosis in up to ten percent of the patients receiving the drug [2-4]. Other less common forms of lung injury such as organizing pneumonia and hypersensitivity pneumonitis may also occur [3]. Risk factors for bleomycin-induced lung injury include cumulative dose, low glomerular filtration rate (GFR), older age, supplemental oxygen exposure, bolus drug delivery, and previous lung disease [5-7,12]. Of these, cumulative dose and reduced renal function are the most well-established risk factors [5,13]. Lung toxicity occurs sporadically at doses less than 450 IU but at doses above this range the incidence rises steeply [5,6]. Smoking is another risk factor for bleomycininduced pulmonary toxicity [14]. Other suggested risk factors include dose rate, combination with other drugs, e.g. cisplatin, radiotherapy and the use of growth factors $[2-4,15,16]$. Since bleomycin itself is a major potential risk factor for lung injury, combined bleomycin and radiotherapy has further contributed to the bleomycin-induced lung injury in our patient.

Our patient was 64 years-old, had a heavy smoking history with a silent chronic obstructive pulmonary disease, received radiotherapy together with a high dose bleomycin. The patient also carried a genetic variation in bleomycin hydrolase gene that was identified after bleomycin lung toxicity had developed. The final diagnosis was pulmonary fibrosis caused by bleomycin that lead to respiratory insufficiency and patient's death. The clinical endpoint of this patient gives rise to the conclusion that patients who undergo bleomycin treatment must be thoroughly evaluated in regard to their pretreatment pulmonary status. Patient history should be exact, must include smoking history and previous lung diseases in a detailed manner. Besides chest $\mathrm{x}$-ray, these patients should undergo a computed tomographic evaluation of the thorax to denote the lung parenchyma for chronic obstructive pulmonary disease, cystic lesions, fibrotic changes, old scars and

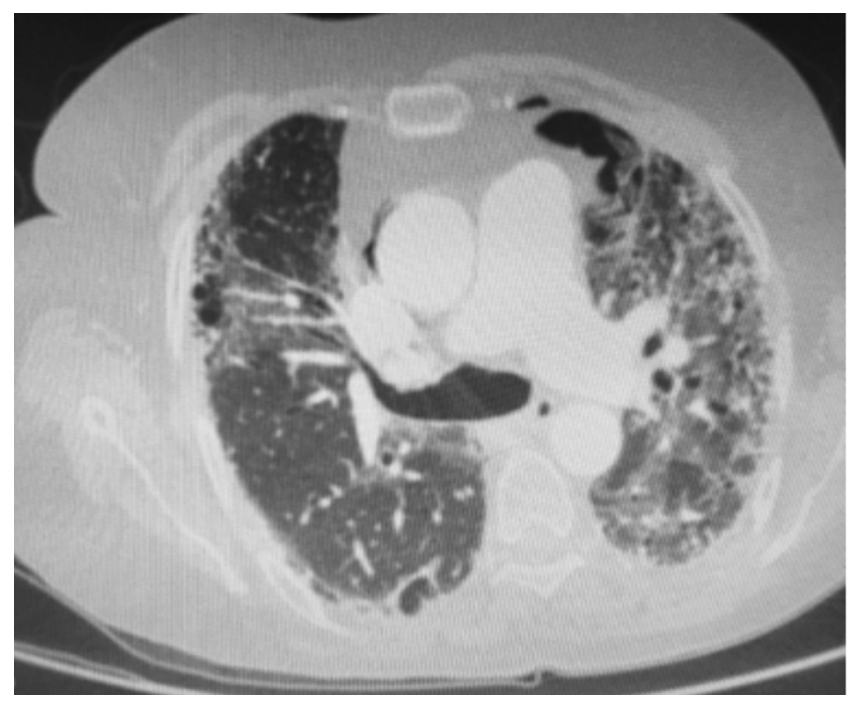

Figure 3. Chest CT showing bilateral diffuse cystic emphysema, ground-glass opacities, traction bronchiectasis, fibrotic bands, and interstitial fibrosis. 
any other probable occult parenchymal lesions or airway diseases. Pulmonary function tests, diffusion capacity and exercise testing should also be performed in equivocal situations. To avoid the combined potential toxicity of radiotherapy and bleomycin induced lung toxicity, these two treatments should be administered separately with a maximum available time interval.

The lung toxicity of bleomycin is well known. The only way to prevent the potential and fatal hazards of this useful drug lies in an elaborate and a meticulous patient evaluation, which is the primary task of the clinician. These patients should be consulted with a pulmonologist for the possible existence of any previous or occult lung disease. Recent data suggests that the overall risk of a clinically apparent severe bleomycin-induced lung injury is low and pulmonary toxicity is reversible without long-term sequela in most of the patients [17,18]. Danish Testicular Cancer database and Lauritsen revealed that only a minority of bleomycin treated patients including those who discontinued bleomycin due to a decrease in carbon monoxide diffusing capacity (DLCO), suffered long-term restrictive disease or obstructive lung disease at five years of follow-up [19,20]. Depending on the clinical criteria and the cumulative bleomycin dose, rates of bleomycin-induced pulmonary toxicity in adults receiving ABVD for Hodgkin lymphoma range from 10 to 53\%, and rates of fatal pulmonary toxicity are 4 to $5 \%$ [13,21], while long-term functional respiratory impairment is observed in approximately 15 to $18 \%$ of the patients [22-25]. The mechanism and pathogenesis of bleomycin-induced lung injury is not fully understood. Oxidative damage, bleomycin hydrolase deficiency, inflammatory cytokines, genetic susceptibility and most importantly the patient related factors as our patient's case, are the hallmark of this syndrome. Whether the risk is minimum or not, the clinicians should pay utmost attention to the jeopardy of bleomycin toxicity, if at all. A comprehensive and an inclusive identification protocol must be used to identify the patients that carry a probable risk factor for pulmonary bleomycin toxicity.

\section{Conclusions}

Our patient had many potential factors that constitute a severe risk for the bleomycin-induced lung toxicity including genetic variation in bleomycin hydrolase gene, old age, smoking history, occult chronic obstructive pulmonary disease, high bleomycin dose and combined radiotherapy. Computed tomography performed at admission revealed chronic obstructive pulmonary lung disease related parenchymal lesions. For patients carrying one or more risk factors for bleomycin-induced pulmonary toxicity, treatment with this agent should be withheld and bleomycin must be replaced by another drug if possible, to prevent the future pulmonary complications of bleomycin toxicity that may be fatal. If treatment with bleomycin is a requisite for the patient, a meticulous clinical search for the presence of a silent or an occult lung disease must be done, while a close and a detailed follow-up should be performed in such patients to cease treatment on time to prevent bleomycin-induced lung toxicity. Asymptomatic patients should also be screened for inherent risk factors that may cause bleomycin-induced pulmonary side effects. We suggest that individuals who are to be treated with bleomycin should undergo a comprehensive and an algorithmic screening surveillance to detect associated risk factors or occult lung disease and to determine the probability of bleomycin-induced lung injury to preclude the severe toxic pulmonary effects of bleomycin treatment. Clinicians should be aware of the bleomycin-induced lung toxicity and identify the possible peril factors before lifethreatening treatment complications develop, especially in patients that carry an identifiable risk factor for bleomycin treatment.

\section{References}

1. Meadors M, Floyd J, Perry MC. Pulmonary toxicity of chemotherapy. Semin Oncol 2006;33:98-105.

2. Azambuja E, Fleck JF, Batista RG, Menna Barreto SS. Bleomycin lung toxicity: who are the patients with increased risk? Pulm Pharmacol Ther 2005; 18:363-6.

3. Sleijfer S. Bleomycin-induced pneumonitis. Chest 2001;120:617-24.

4. O'Sullivan JM, Huddart RA, Norman AR, et al. Predicting the risk of bleomycin lung toxicity in patients with germ-cell tumours. Ann Oncol 2003;14:91-6.

5. Comis RL. Bleomycin pulmonary toxicity: current status and future directions. Semin Oncol 1992;19(Suppl 5):64-70.

6. Goldiner PL, Carlon GC, Cvitkovic E, et al. Factors influencing postoperative morbidity and mortality in patients treated with bleomycin. Br Med J 1978;1:1664-7.

7. Reinert T, Baldotto CS, Nunes FAP, Scheliga AA. Bleomycin induced lung injury. J Cancer Res 2013;2013:1-9.

8. Filderman AE, Genovese LA, Lazo JS. Alterations in pulmonary protective enzymes following systemic bleomycin treatment in mice. Biochem Pharmacol 1988;37:1111-6.

9. Harrison JH Jr, Hoyt DG, Lazo JS. Acute pulmonary toxicity of bleomycin: DNA scission and matrix protein mRNA levels in bleomycin-sensitive and -resistant strains of mice. Mol Pharmacol 1989;36:231-8.

10. Hoyt DG, Lazo JS. Murine strain differences in acute lung injury and activation of poly(ADP-ribose) polymerase by in vitro exposure of lung slices to bleomycin. Am J Respir Cell Mol Biol 1992;7:645-51.

11. Schrier DJ, Kunkel RG, Phan SH. The role of strain variation in murine bleomycin-induced pulmonary fibrosis. Am Rev Respir Dis 1983;127:63-6.

12. Phan SH, Kunkel SL. Lung cytokine production in bleomycininduced pulmonary fibrosis. Exp Lung Res 1992;18:29-43.

13. Martin GW, Ristow KM, Habermann MT, et al. Bleomycin pulmonary toxicity has a negative impact on the outcome of patients with Hodgkin's lymphoma. J Clin Oncol 2005;23:7614-20.

14. Hansen SW, Groth S, Sorensen PG, et al. Enhanced pulmonary toxicity in smokers with germ-cell cancer treated with cisplatinum, vinblastine and bleomycin: a long-term follow-up. Eur J Cancer Clin Oncol 1989;25:733-6.

15. Couderc LJ, Stelianides S, Frachon I, et al. Pulmonary toxicity of chemotherapy and G/GM-CSF: a report of five cases. Respir Med 1999;93:65-8.

16. Lei KI, Leung WT, Johnson PJ. Serious pulmonary complications in patients receiving recombinant granulocyte colony-stimulating factor during BACOP chemotherapy for aggressive non-Hodgkin's lymphoma. Br J Cancer 1994;70:1009-13.

17. Necchi A, Miceli R, Oualla K, et al. Effect of bleomycin administration on the development of pulmonary toxicity in patients with metastatic germ cell tumors receiving first-line chemotherapy: A meta-analysis of randomized studies. Clin Genitourin Cancer 2017;5:213-20.

18. Lauritsen J, Kier MG, Bandak M, et al. Pulmonary function in patients with germ cell cancer treated with bleomycin, etoposide, and cisplatin. J Clin Oncol 2016;34:1492-9.

19. Daugaard G, Kier MGG, Bandak M, et al. The Danish Testicular Database. Clin Epidemiol 2016;8:703-7.

20. Ranganath P, Kesler KA, Einhorn LH. perioperative morbidity and mortality associated with bleomycin in primary mediastinal nonseminomatous germ cell tumor. J Clin Oncol 2016;34:4445-6. 
21. Hirsch A, Vander Els N, Straus DJ, et al. Effect of ABVD chemotherapy with and without mantle or mediastinal irradiation on pulmonary function and symptoms in early-stage Hodgkin's disease. J Clin Oncol 1996;14:1297-305.

22. Hoskin PJ, Lowry L, Horwich A, et al. Randomized comparison of the Stanford V regimen and ABVD in the treatment of advanced Hodgkin's Lymphoma: United Kingdom National Cancer Research Institute Lymphoma Group Study ISRCTN 64141244. J Clin Oncol $2009 ; 27: 5390-6$.
23. Sun HL, Atenafu EG, Tsang R, et al. Bleomycin pulmonary toxicity does not adversely affect the outcome of patients with Hodgkin lymphoma. Leuk Lymphoma 2017;58:2607-14.

24. Jóna Á, Miltényi Z, Ujj Z, et al. Late pulmonary complications of treating Hodgkin lymphoma: bleomycin-induced toxicity. Expert Opin Drug Saf 2014;13:1291-7.

25. Avivi I, Hardak E, Shaham B, et al. Low incidence of long-term respiratory impairment in Hodgkin lymphoma survivors. Ann Hematol 2012;91:215-21. 